\title{
Sphero Robotics and STEAM Education in Diploma Level: A Pilot Study Using Sphero Robotics Module for Problem Solving and Program Design Course
}

\author{
Jacey d/o Mariadass a , Astri Idayu Binti Athesan ${ }^{\mathrm{b}}$, \\ Mohd Faizul Emizal Bin Mohd Ghazi ${ }^{* *}$ \\ ajacey@puo.edu.my, ${ }^{b}$ astriidayu@puo.edu.my, ${ }^{c}$ mfaizulemizal@puo.edu.my \\ Lecturer, Department of Information and Communication Technology, \\ Polytechnic Ungku Omar, Malaysia
}

\begin{abstract}
The purpose of this study is to find the impact of utilizing Sphero Robotic as an educational aid for DFC10042 Problem Solving and Program Design (PSPD) course to teach basic principles of Programming. For this purpose, a module is developed to be use with Sphero Robotic. The robotic was used in the frame of the STEAM education approach. STEAM Education is an approach towards learning that uses Science, Technology, Engineering, Arts and Mathematics as access points for guiding student's inquiry, dialogue, and critical thinking. Sphero robotics is proven to be an important educational aid to achieve these goals. This study was conducted by using a quasi-experimental design with pre-test and post-test groups combine with survey method to obtain feedback from the participants. The study group consists of 61 PSPD course students (control group, 30; treatment group, 31). Questionnaire were given after post-test for the treatment group. The control group were following conventional teaching and learning where else the treatment group were using Sphero Robotics Module. Within this the students are asked to work in groups to design, develop and implement their programs to control the behavior of Sphero Robotics with the specially developed module. The result for post-test shows the treatment group obtained increment in percentage as $22 \%$ compared to control group. The feedback from questionnaire shows that this type of learning environment increases students' motivation to participate in an active way in learning. Besides that, the findings show Sphero Robotics module can help to gain students attention to perform better in the course. Therefore, the outcome shows that Sphero Robotic Module developed for PSPD course can be a promising and innovative education aid for educators to engage with their students in creative and attractive learning.
\end{abstract}

"Keywords: Sphero Robotic; Student Motivation; Student Attention; Student Performance"

\section{Introduction}

The exploitation and assimilation of technology in 21st century takes place through satisfying environment of learning. Lecturers need to be innovative in designing their pedagogical approach so that students can perform well in the course taken. Traditional activities without hands-on activities in the classroom lead to a boring feeling among the students and they fail to achieve educational outcomes. 
Technology advancements have helped to nurture the hands-on concepts without limiting its accessibility towards location, space, and cost. This supported facility comes together with the endless access of information through the internet. Now the challenge arises among educators on how to make the learning environment interesting through the exploitation of technology. Study done by Fojtik, (2017) shown that the instructor's teaching style and a student's learning style must be coordinated to produce a conducive learning environment.

Learning is an ongoing process encountered by people all over the world. Learning is defined as the acquisition of knowledge or skills through study, experience or being taught to achieve certain understanding on a concept. The learning process can be instant, made by a single incident but practically most of the skill and knowledge are effectual from repeated and hands-on approach experiences.

Problem-based learning (PBL) within a STEAM curriculum could enhance students' desire to understand the world around them and engage them in classroom instruction. PBL uses method from studentcentered approach in which students learn about a subject by working in groups to solve an open-ended problem. Skills like problem solving, creativity, motivation and attention are positively influenced when students access technology in their learning environments. A study in one of higher education institutions shows students' performance have increased and obtain the greatest benefit from experiential and studentcentered learning approaches. Their analysis suggests that PBL have act as a mediator to encourage the learning process (Jabarullah and Iqbal Hussain, 2019). Students able to retain computer knowledge when they obtain hands-on learning experience.

Exposing the students to relevant adaptive learning may lead to higher retention of student motivation and attention in computing. As robotics is becoming a more effective way to engage students with coding and programming, many studies propose that robotics should be integrated with the curriculum. Besides that, according to Eguchi (2014), the use of robots helps to reinforce students' soft skills such as teamwork, critical and creative thinking, problem solving and algorithmic patterned thinking.

Therefore, this study is conducted to investigate whether the use of Sphero Robotics could enhance learning environment for PSPD course among Diploma in Information Technology (Digital Technology) students. The following research questions (RQs) were defined to achieve the purpose of this research: (i) to identify students' perception on the use of Sphero Robotics module in PSPD course in terms of: (a) motivation, (b) attention, and (ii) to identify whether the use of Sphero Robotics Module in PSPD course could help students to perform better in this course. Figure 1 shows the framework for the study conducted. In 
this paper the results of a quasi-experiment were conducted to investigate the effectiveness of implementing Sphero Robotics Module. The rest of this paper is organized as follows; (i) Section 2 present the literature review (ii) Section 3 presents research methodology, (iii) Section 4 presents the findings results from the questionnaire and quasi-experiment. Section 5 concludes the paper.

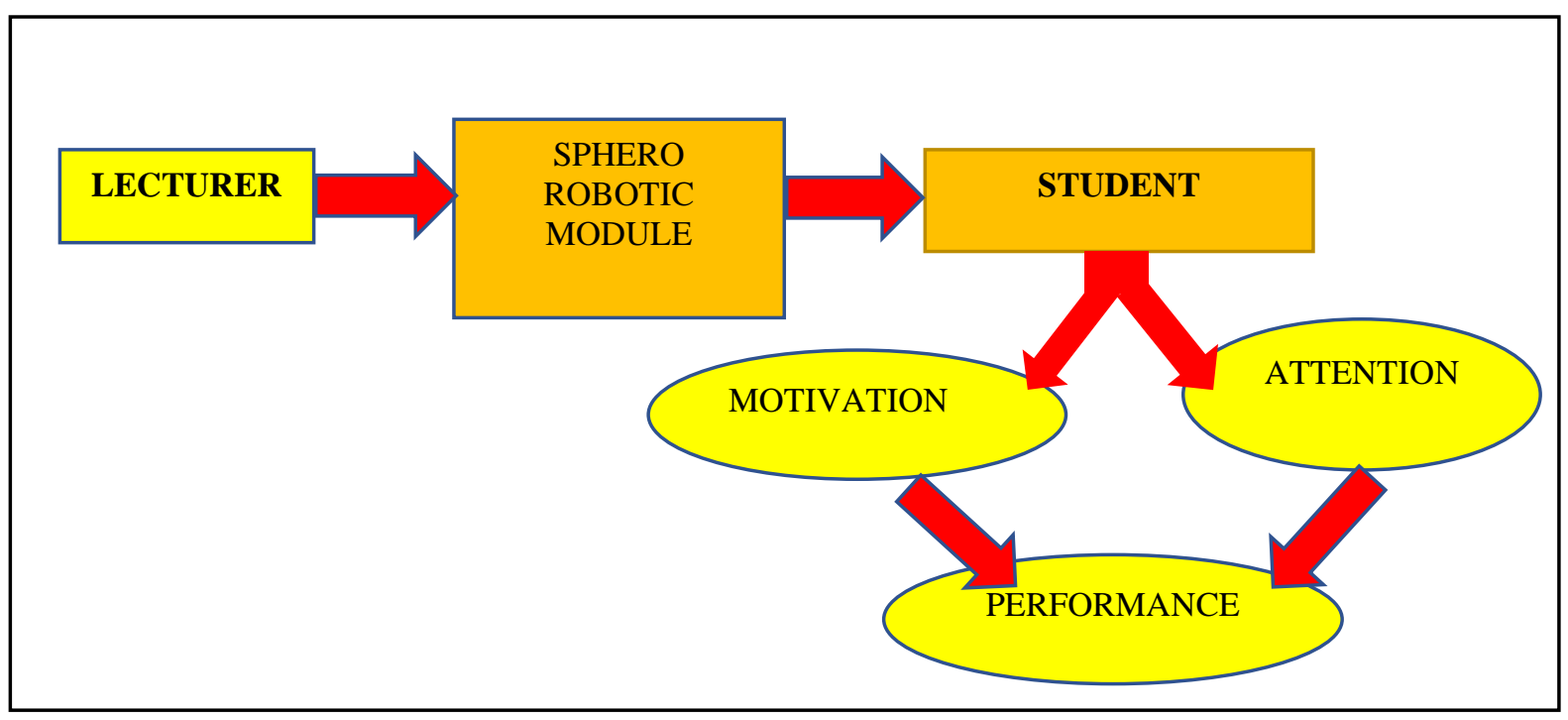

Fig. 1.: Framework of the study conducted

\section{Literature Review}

\subsection{Teaching and Learning}

In the era of globalization growth, the use of information technology is also in demand. New generations are well-known as gadget-geek and are pre-exposed to this idea of technology as part of their everyday chores. When it comes to learning, conventional teaching methods have long loss its flickers in attracting the techno-base students. Instead, educators need a more dynamic and creative approach which stays relevant to teaching contents in accordance with current developments.

The learning process should involve technology as the supportive tools or even as main mediator. The 'chalk and talk' method are not even comparable to how technology able to stimulate involvement in teaching ang learning. The concepts point out that changes in education should correspond to the development era or be anticipate ahead of time (Norhafidzah, 2015). 
Educational technology is enhanced by using intermediary instruments as teaching aids to understand a context, especially in program learning. The impact of ICT in education has been proven in various studies to be able to make teaching and learning activities more interesting, motivating, and meaningful. The effectiveness of problem solving in terms of programming is seen from the ability of students to understand the methods of Computational Thinking (CT). According to Enrico (2019), CT is an entry point to shift from solving problems to having problems solved as the fundamental contribution of computing to science.

\subsection{Computational Model}

Education which is the key to all forms of connections have also shifted towards digitization. Envisioning computing education in teaching will empowers the education. Learners needs to change their way of thinking not to only what problems are to be solved, but also how they are solved. According to (Tenre and Denning, 2016), CT covers two aspects of concepts when it comes to problem solving: (i) mimicking the computational thinking of machine (ii) interpreting on how information will be processed.

An outcome of this way of thinking will produce a computational model. Define as the compilation of programming language written to allow machine to operate (Denning and Tendre, 2019). Having them operate on an abstract machine (hardware or software), allows the model to be analysed and produce an outcome. It simulates the problem solving through the execution to helps better understanding of natural information that is being processed by learners.

\subsection{Sphero Robotic}

To help students familiar with the basic principles in Programming, educational robotics have played an important role (Stergiopoulou, Karatrantou and Panagiotakopoulos, 2017). Programming robotic constructions creates a completely new learning environment which is highly motivating. In current education system, robots have been proven having the opportunity to enhanced students learning environment. This is because their innovative character and the hands-on experience they offer makes students more interested in learning. The program's use of robotics facilitated the recommended hands-on learning experience within all activities as students had to program and control their own balls as well as work in teams (Stefanut \& Tripon, 2017). To help students to visualize the natural information process by them during Problem Based Learning (PBL), an education tool namely Sphero Robot or known as Sphero Edu is used. The computational model that has been generated (replica of the natural information process) will be brought through the simulation of 
how Sphero functions. The Sphero is very engaging for students as it can move quite quickly and have programmable and colour changing LED inside it.

Sphero Edu uses app-enabled robots to foster creativity through discovery and play, while still manage to place computer science education as the foundation. Through the class activities, usually the engagement of STEAM concepts in education will be applied as it provides diversity and it is expected to impact to a more effective learning process towards different learning style.

Most of the activities involved Project Based Learning which stimulates the autonomous learning needed for the $21 \mathrm{st}$ Century skills. Students with autonomous learning could take control of one's own learning, independently or in collaboration with others. An autonomous learner will take more responsibility for learning and is likely to be more effective than a learner who is reliant on the teacher. The autonomous learning is said to be comparable to 'independent learning' that uses along the facility of technology-based learning (Ahmadzadeh and Zabardast, 2014).

To support wide range of users that consist of different type of learning style and age level, this learning tool uses three customs of controlling the robot that includes 'canvases' of Draw, Block, and Text. Figure 2 shows the interface of each canvases. The Draw canvases use the approach of drawing interface while Block canvases uses a drag-and-drop block interface and teaches the logical structure of code. For advance learners, the Text canvases applies the programming language JavaScript that focuses on computer science and programming.

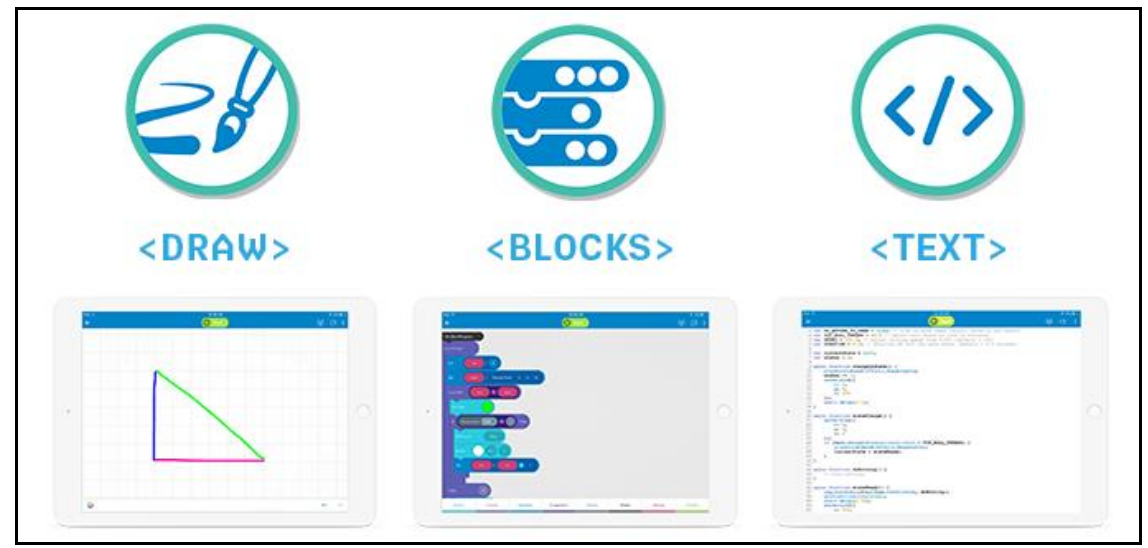

Fig. 2.: Canvases available in Sphero Edu 
By considering the factors students only have a basic knowledge of programming, only Draw and Blocks are use inside the module. Each approach allows users to create programs by manipulating program elements graphically rather than by specifying them textually. It also helps students to visualize the outcome in real-time base for them to evaluate the solution that they have figured during PBL either visually (web base) or physically through the Sphero Edu robot.

\subsection{Motivation, attention and learning performance}

Students are motivated in learning process if they get involved by themselves. They can stay motivated if they are given hands-on activity and see the output from the activity given. According to KalotiHallak, Armoni and Ben-Ari (2015), educators should give students basic knowledge about robotics before educator uses this approach for teaching and learning. After they obtain basic knowledge, students need to be given real problems for them to solve it through competition. Based on the research done by Lauwers, Nourbakhsh and Hamner, (2009), students' positive attitudes and motivation has increased when they learn with robotics activities. Besides that, the students are able to complete all the assignments and tests scores and the study shows that the result were significantly higher than in previous years.

It is a great benefit for students if the educator integrate teaching and learning with robotics. Based on the research done by Tejada et.al (2020), by using robotics in teaching and learning, it could lead to increased motivation level and able to capture the attention and interest of the students. The use of robots in education can attract students attention, entertain the students and improve their memory, logical and attention. This situation indirectly could help students to obtain better grade for the course taken.

As mentioned above, the use of robotic in education has a lot to offer to the students as well as the educators. Many research have been proven that the use of robotic in education have positively contributed to the increase of students' motivation, their focus in learning, their creativity and their positive attitude towards education and its subjects through problem solving circumstances. 


\section{Research Methodology}

\subsection{Participants}

The study is conducted using purposive sampling where samples are chosen among the whole population based on the purpose of the study. The study was conducted among the first semester Diploma Information Technology (Digital Technology) students in Polytechnic Ungku Omar, Malaysia. The samples are the students from the two classes of the Problem Solving and Program Design Course. A Total of 61 students were involved in this research.

\subsection{Research design}

The study uses quasi-experimental method and survey method. Both methods are used based on the relevance of the study. The researcher uses quasi-experimental studies in order to know the impact of using Sphero Robotic Module for PSPD course. This design consists of two groups that is control group and treatment group. Figure 2 shows the procedure used by the researcher. Both groups were given a pre-test. After the pre-test, control group used conventional method in teaching and learning while the treatment group used Sphero Robotic as an education aid. The post-test were given after they learn through the method used from each group. It is done in order to see the effectiveness of each method used. The questions for the pretest and post-test were standardized in order to avoid biasness between both groups. The questions were created by the course-coordinator. After both groups did their post-test, questionnaire were given to the treatment group to assess their perception on the use of Sphero Robotic Module in terms of motivation and attention. Data were analysed using Statistical Package for Social Science software. Figure 3 shows pre-test and post-test implementation procedures. 


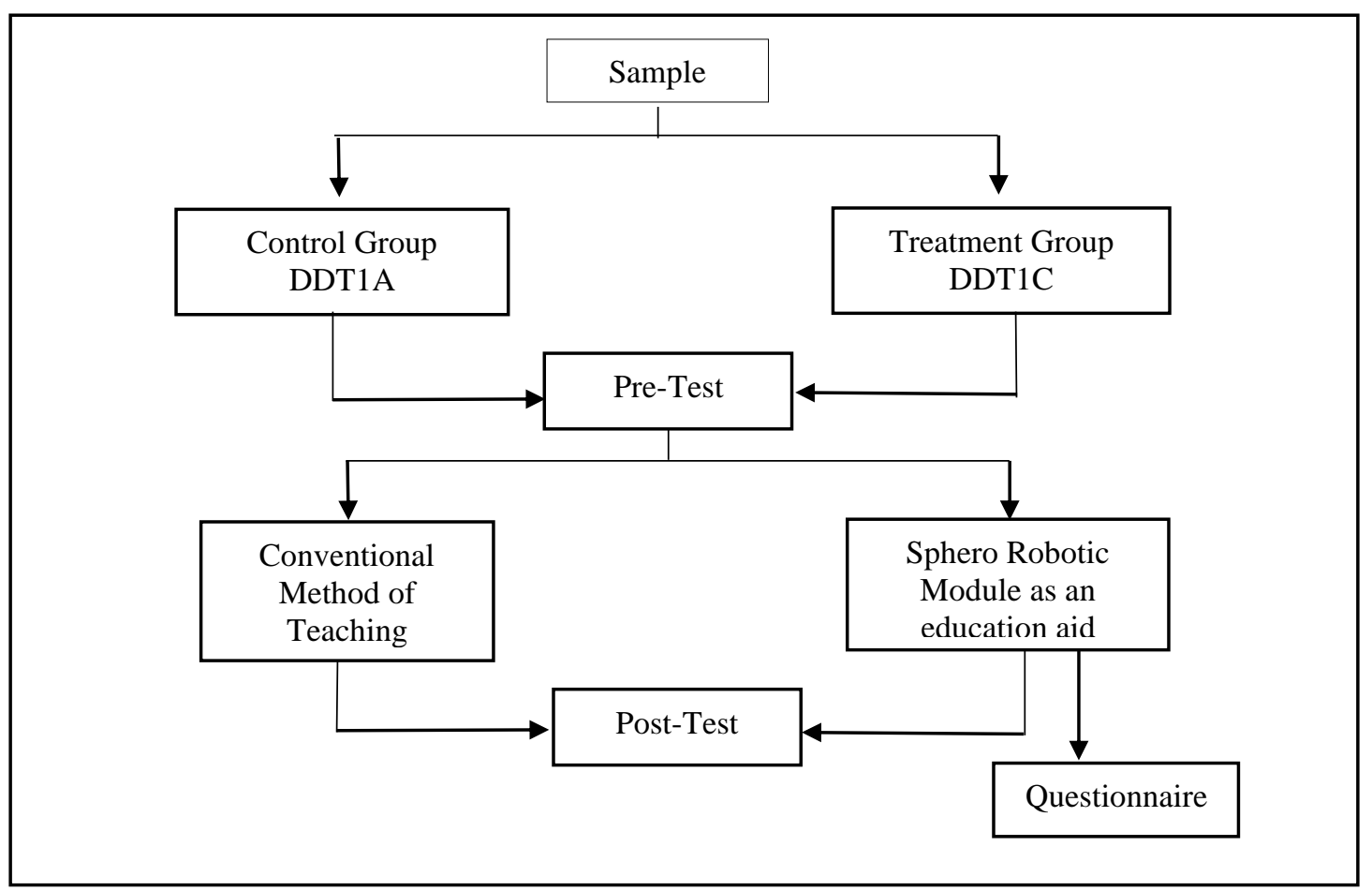

Fig. 3: Pre-test and post-test implementation procedures

Statistic descriptive was used in this studies in order to explain students' response through questionnaire. The survey consisted of two main sections: (i) a demographic data section to gather information concerning the participants' age, gender and (ii) a five-point Likert scale survey section where 1 meant strongly disagree and 5 stood for completely agree. The second session is divided into two dimensions; (i) motivation and (ii) attention. Students' performance were evaluated based on pre-test and post-test conducted between control group and treatment group.

\subsection{Data analysis}

The results obtained from pre-test and post-test were analyzed using Statistical Package for Social Science. The marks were analyzed by finding the percentage to see whether there is an increase between control group and treatment group. The percentage for overall marks for pre-test and post-test are sought to see whether the implementation of Sphero Robotic Module was able to motivate and help them to stay focus and to perform better in the course.

Data analysis was performed descriptively. Likert scale is used to measure the response given for each item in the questionnaire. Participants have to tick their answer chosen for each item in the questionnaire 
based on the scale which is strongly disagree to strongly agree. Table 1 shows the likert scale used for this study.

Table 1. Likert scale

\begin{tabular}{lll}
\hline Score & Level of acceptance & Symbol \\
\hline 1 & Strongly Disagree & SD \\
2 & Disagree & D \\
3 & Not Sure & NS \\
4 & Agree & A \\
5 & Strongly Agree & SA \\
\hline
\end{tabular}

The responses obtain from the questionnaire were analyzed in order based on items in section A, B and C. All data obtained from the participants were collected and analyzed quantitatively. All the data were analyzed using Statistical Package for the Social Sciences (SPSS). The percentage for section B and C was made to find out the perception of participants whether the use of Sphero Robotic Module could increase students motivation level and keep them focused in learning this course.

\section{Findings}

This section comprises the discussion of data analysis from the responses given by the participants. Besides that, this section also consists of the findings regarding students' performance due to the ability to retain understanding and knowledge of the course taken due to the implementation of Sphero Robotic Module. The result are displayed in chart and table form which consist of frequency and percentage.

\subsection{Section A analysis: Student demographic}

The item for this section are participants' gender, ethnic group and their like towards programming language. Figure 4 shows the demographic (gender) distribution of the participants in this study. 19 (61\%) participants are male while female are $13(39 \%)$ participants. 


\section{DEMOGRAPHIC (GENDER DISTRIBUTION)}

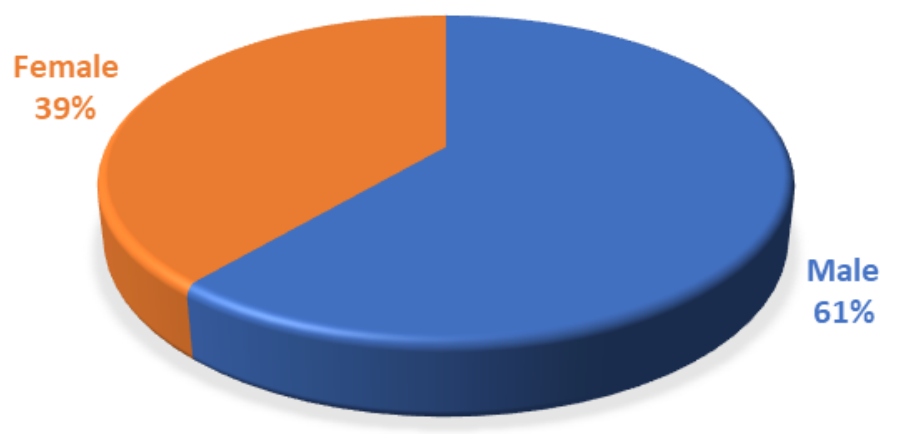

Fig. 4. Demographic (gender) distribution

Figure 5 shows the participation demographic distribution based on ethnic group. 26(84\%) of the participations are Malay and 5(16\%) are Indian.

\section{DEMOGRAPHIC (ETHNIC DISTRIBUTION)}

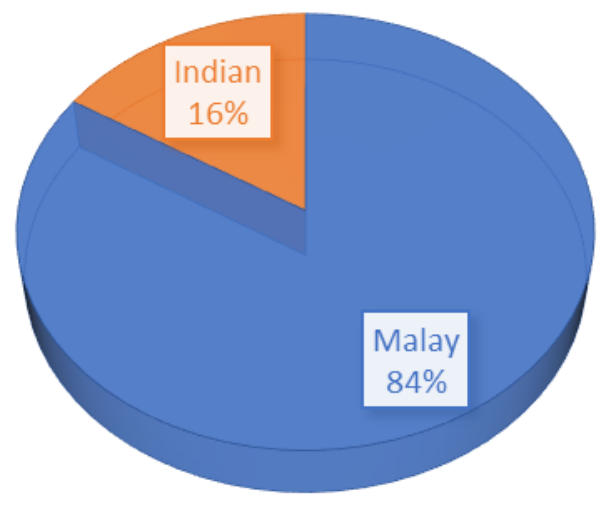

Fig.5. Demographic (ethnic) distribution 
Table 2 shows the participants likelihood of programming language. 21 (67.7\%) like programming language while 10 (32.3\%) doesn’t like programming language.

Table 2. Participants likelihood (Programming Language)

\begin{tabular}{llll}
\hline Likelihood & Yes & 21 & $67.7 \%$ \\
\cline { 2 - 4 } $\begin{array}{l}\text { (Programming } \\
\text { Language) }\end{array}$ & No & 10 & $32.3 \%$ \\
\hline
\end{tabular}

Figure 6 shows the percentages of the results for pre-test and post-test for both classes. The pre-test result shows that both group are in the same level. It is shown that the percentage of the results for pre-test is $61 \%$ while the treatment group obtained $60.3 \%$. Students' performance for post-test shows increment in students' performance in treatment group compared to the control group which is $22 \%$. The result shows that the use of this module can lead to better performance for this course.

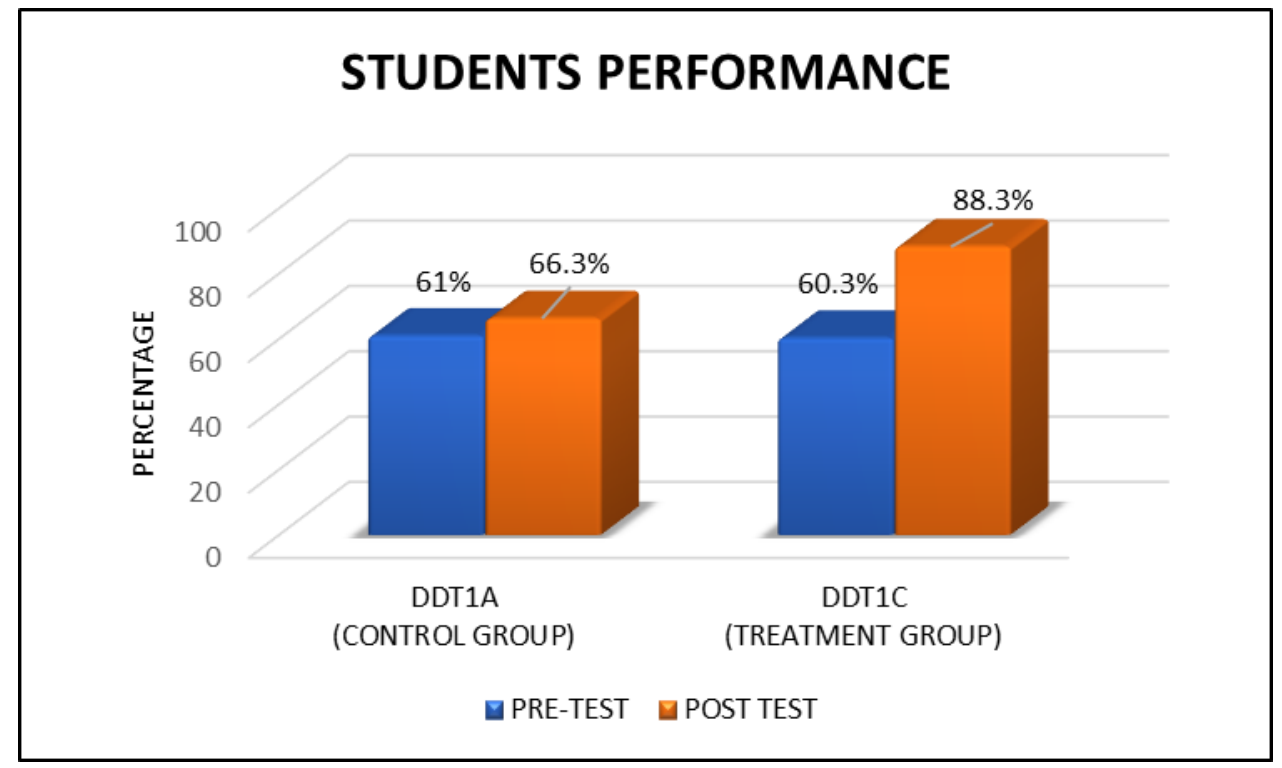

Fig. 6.: Students performance for pre-test and post-test 
4.2 Section B analysis: Students perception towards the implementation of Sphero Robotic Module related to student's motivation

In this section, the items were used to get participants perception towards the implementation of Sphero Robotic Module related to their motivation. Table 3 shows the item used to assess student's motivation after they complete the module developed by the researchers.

Table 3: Item to assess students motivation

\begin{tabular}{|c|c|}
\hline \# & Item \\
\hline 1. & The use of Sphero helps me to reduce tension. \\
\hline 2. & I put my best effort in PSPD course to perform good result. \\
\hline 3. & The use of Sphero is really interesting in motivating myself. \\
\hline 4. & The experience I found throughout my learning process on the course aroused my curiosity. \\
\hline 5. & The learning environment using Sphero is challenging. \\
\hline 6. & $\begin{array}{l}\text { I like when my lecturer use Sphero to show the application of programming language in real } \\
\text { situation. }\end{array}$ \\
\hline 7. & I feel the task given to me by lecturer gives me positive contribution to my learning. \\
\hline 8. & By using Sphero for PSPD course, the opportunity of interacting with the lecturer is enhanced. \\
\hline 9. & $\begin{array}{l}\text { By using Sphero for PSPD course, the opportunity of interacting with my classmates is } \\
\text { enhanced. }\end{array}$ \\
\hline 10. & The use of Sphero is really interesting in motivating myself in learning programming language. \\
\hline
\end{tabular}


Figure 7 shows student learning environment from motivation aspect.

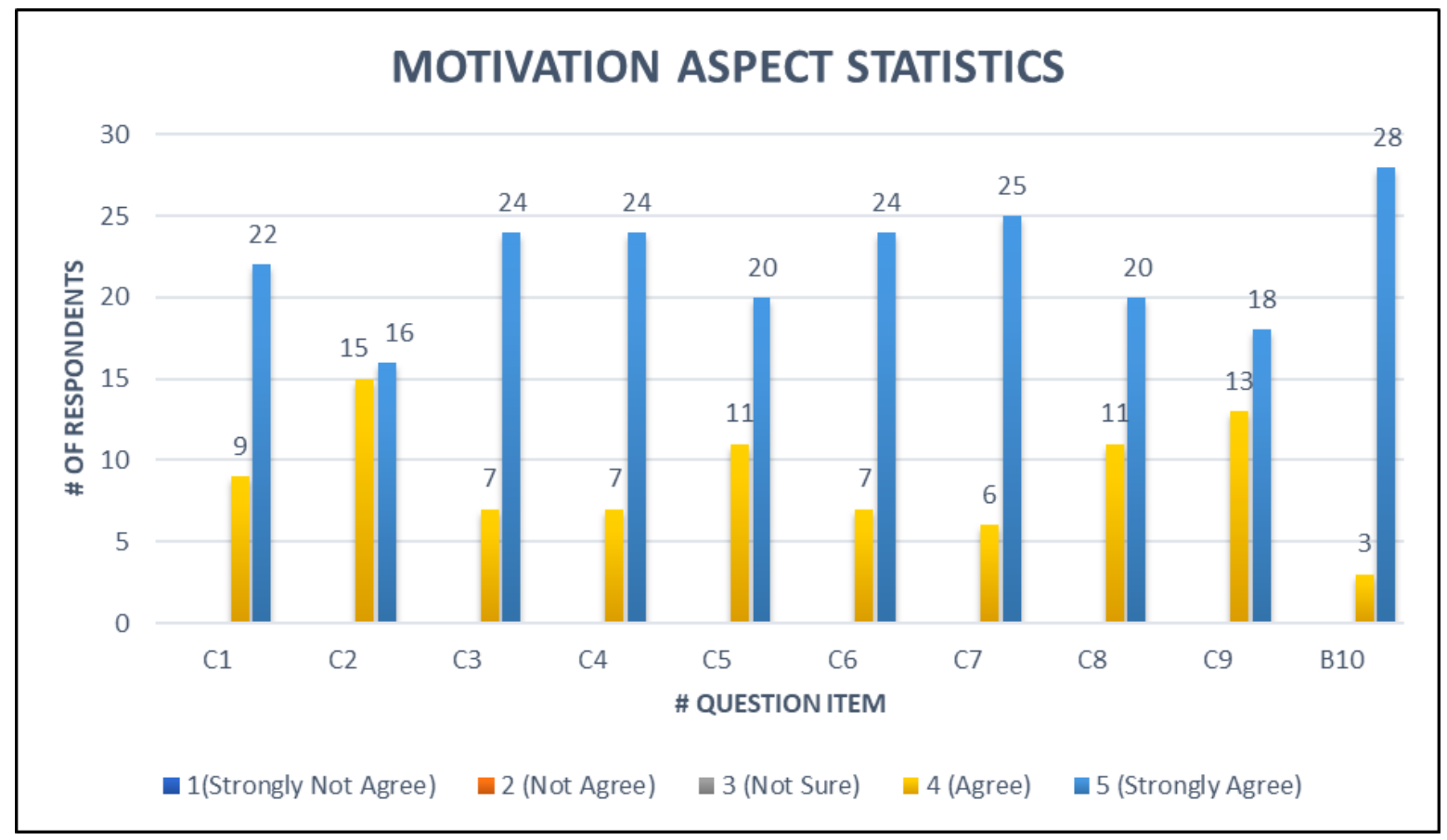

Fig. 7.: Motivation aspect

The statistics result of students motivation aspect shown in Figure 7. All the items to access students motivation shows that students chooses between agree and strongly agree only. This result shows that they can enhanced their learning environment through the use of the module developed by the innovators. As a conclusion, the findings shows $80 \%$ that is equal to 8 out of 10 questions achieved above 20 respondents that answer with score 5.This shows that the use of Sphero Robotic Module motivates the students in order to enhance their learning environment to study PSPD course.

\subsection{Section C analysis: Students perception towards the implementation of Sphero Robotic Module related to students attention}

The data analysis in this section is regarding students' perception towards the implementation of Sphero Robotic Module towards students attention. Table 4 shows participants' perception towards the aspect of attention. 
Table 4 shows the item used to assess students attention

Table 4: Item to assess student attention

\begin{tabular}{|c|l|}
\hline$\#$ & Item \\
\hline 1. & I felt in control of my learning process. \\
\hline 2. & I felt having fun when using Sphero. \\
\hline 3. & It was easy to understand and relate programming application in real life situation. \\
\hline 4. & I felt confidence in myself to learn programming language. \\
\hline 5. & The use of Sphero has practical value for me. \\
\hline 6. & The use of Sphero encourages me to learn programming language in depth. \\
\hline 7. & $\begin{array}{l}\text { I think the lecturer using Sphero in teaching PSPD helps me to improve my skill in } \\
\text { programming language. }\end{array}$ \\
\hline 8. & I felt my learning experience was meaningful. \\
\hline 9. & Sphero makes me more interested in learning PSPD. \\
\hline 10. & The use of Sphero helps to hold my attention throughout the course. \\
\hline
\end{tabular}

Figure 8 shows students attention feedback.

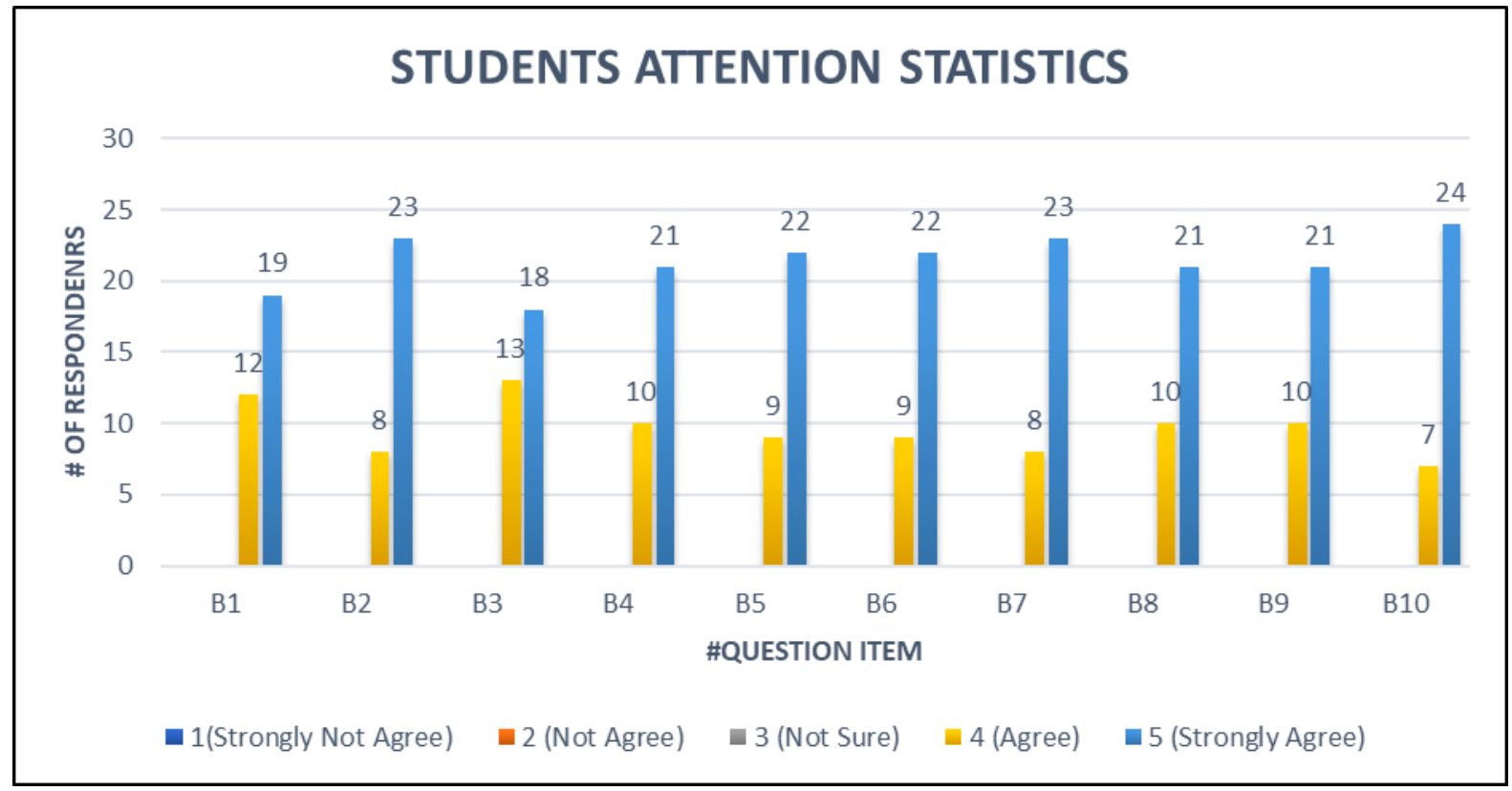

Fig. 8.: Students attention statistics 
The statistics result of students attention towards the use of module to be used with Sphero Robotic for PSPD shown in Figure 8. All the items to access students attention shows that students chooses between agree and strongly agree only. This result shows that they can enhanced their learning environment through the use of the module developed by the innovators. As a conclusion, $80 \%$ that is equal to 8 out of 10 questions achieved above 20 respondents that answer with score 5. This shows that this module which is used with Sphero Robotic is getting a good response from students in order to enhance their learning environment when studying PSPD course.

At the end of semester, the effectiveness of the tools are measured from the Course Learning Outcome Review Report (CLORR) that is measured on Course Learning Outcome (CLO). The treatment group showed a higher percentage of Average Group Attainment to achieve above $80 \%$. This proofs that students can perform better due to improved understanding derived from the implementation of this innovation.

\section{Conclusion}

The innovation have proved that good education application relies on good design of module that contributes to the improvement of students motivation and attention to study. Besides that, the students can perform well in PSPD course which will be helpful for the enrolment Programming Fundamental course in semester 2. This is because, PSPD course is the pre-requisite for Programming Fundamental course. In order to perform well in Programming Fundamental course, students need to grasp positive values towards learning process. The development of module for Sphero Robotic is able to enhance students learning environment for PSPD course.

\section{Acknowledgements}

We would like to thank ICT Department, PUO for allowing me to conduct this study and my greatest appreciation to all participants who had participated in this study.

\section{References}

Ahmadzadeh, R., Zabardast, S., 2014. Learner Autonomy in Practice. International Journal on New Trends in Education and Their Implications, vol 5, No. 4.

Eguchi, A., 2014. Educational Robotics for Promoting 21st Century Skills. Journal of Automation Mobile Robotics and Intelligent Systems, vol. 8, no. 1, p. 5-11.

Enrico, N., 2019. Do we really need computational thinking?. Publication: Communications of the ACM https://doi.org/10.1145/3231587

Fojtik, R., 2017. The Ozobot and education of programming. New Trends and Issues Proceedings on Humanities and Social Sciences.vol. 05, p $08-16$. 
Jabarullah, N.H. and Iqbal Hussain, H., 2019. The Effectiveness of Problem-based Learning in Technical and Vocational Education in Malaysia, Education + Training, vol. 61, no. 5, p. 552-567. https://doi.org/10.1108/ET-06-2018-0129

Kaloti H.F., Armoni, M., \& Ben, A.M.M., 2015. Students' Attitudes and Motivation during Robotics Activities. Proceedings of the Workshop in Primary and Secondary Computing Education (ACM), p. 102-110.

Lauwers, T., Nourbakhsh, I., Hamner, I., 2009. CSbots: Design and Deployment of a Robot Designed for the CS1 Classroom. ACM SIGCSE Bulletin, vol. 41, no. 1, p. 428-432.

Norhafidzah, A. (2015, October 31). Teaching and Learning in the 21st Century. Retrieved April 10, 2016, from

Blogspot.com: http://feezaupsi15.blogspot.my/ 2015/10/pengajaran-dan-pembelajaran-abad-ke-21.html

Stefanut, T., Tripon, A.C., 2017. Educational Mobile Application using Sphero SPRK+ in an Augmented Reality. Scenario Revista Romana de Interactiune Om-Calculator. Vol. 10, no. 3, p. 231-249.

Stergiopoulou, M., Karatrantou, A., and Panagiotakopoulos., 2017. Educational Robotics and STEM Education in Primary Education: A Pilot Study Using the H\&S Electronic Systems Platform, Advances in Intelligent Systems and Computing no. 560, p. 88-103 DOI: $10.1007 / 978-3-319-55553-9+7$

Tedre, Matti; Denning, Peter J., 2016. The Long Quest for Computational Thinking. Proceedings of the 16th Koli Calling Conference on Computing Education Research, November 24-27, 2016, Koli, Finland: pp. 120-129.

Tejada, J.E., Larico1, S.P., Urda, B.L., Carpio1. A.F., Paredes, K.R., 2020. Interactive Toy to Strengthen the Memory, Attention and Logic of Primary Education Students Using Sphero, Arduino and Neurosky Mindwave EEG. http://ceur-ws.org/Vol-2747/paper23 